\title{
Effect on the intraocular pressure of hypotensive anaesthesia with intravenous trimetaphan
}

\author{
P. L. R. DIAS, D. S. ANDREW, AND G. J. ROMANES \\ From the Royal Eye Infirmary, Weymouth
}

SUMMARY The intraocular pressure was measured at 5-minute intervals with a Perkins applanation tonometer in 5 patients undergoing routine dacryocystorhinostomy under low-tension anaesthesia with a continuous intravenous infusion of trimetaphan (Arfonad), the systolic pressure being maintained at $60 \mathrm{mmHg}$. Twelve patients undergoing cataract surgery under the same premedication and anaesthesia but in whom the systemic blood pressure was maintained at normal levels served as controls. A sudden and dramatic lowering of the intraocular pressure to very low levels was noted when the systolic blood pressure was reduced to $60 \mathrm{mmHg}$. It seems likely that a collapse of the choroidal circulation rather than a decreased aqueous formation due to low perfusion pressure is the most likely cause of the sudden lowering of intraocular pressure.

Transient changes in intraocular pressure related to abrupt changes in systemic blood pressure possibly arising from changes in ocular blood volume have been described. ${ }^{1}$ Variations in blood pressure produced alterations in the ocular blood flow, and Bill ${ }^{2}$ and Cohan and Cohan ${ }^{3}$ showed that the blood flow through the uveal tract varied directly with the level of systemic arterial pressure. Adler ${ }^{4}$ showed that artifically induced changes in systemic blood pressure in animals were accompanied by parallel changes in the intraocular pressure, which were exaggerated if the cervical sympathetic trunk was divided. There is little doubt that ocular blood flow is influenced mainly by the systemic arterial pressure, lowering of which is bound to produce a fall in intraocular pressure.

Anaesthetic procedures are also known to cause alterations in intraocular pressure. Laryngoscopy and intubation caused a rise in intraocular pressure, ${ }^{5}$ while intravenous induction agents caused a fall in intraocular pressure, ${ }^{6}$ with the exception of ketamine, which had the opposite effect. ${ }^{7}$ Intravenous suxamethonium caused a rise in intraocular pressure, while thiopentone sodium increased facility of outflow and so lowered the intraocular pressure. ${ }^{8}$ Thus the intraocular pressure at the time of anaesthetic induction is subject to much variation.

Ganglion blocking agents like hexamethonium bromide (Vegolysen) given by intravenous infusion

Correspondence to Mr G. J. Romanes, Royal Eye Infirmary. 9 Greenhill, Weymouth. Dorset DT4 7TB. to lower systemic blood pressure to $90 \mathrm{mmHg}$ were found to lower the raised intraocular pressure in patients with acute glaucoma to normal levels. ${ }^{910}$ In hypertensive subjects pentolinium or hexamethonium bromide produced average falls of $9 \mathrm{mmHg}$ in the intraocular pressure. ${ }^{11}$ Niesel $^{12}$ found that hexamethonium given intravenously to rabbits always reduced the systemic blood pressure, intraocular pressure, and choroidal blood flow. Thus ganglion blocking agents which cause a fall in blood pressure also cause a fall in intraocular pressure, but with some drugs like intravenous tetraethyl ammonium bromide the fall in intraocular pressure was of a greater degree than could be explained by a mere fall in blood pressure ${ }^{13}$ and this suggests that, though the fall in intraocular pressure may be secondary to the systemic changes in the circulation, the ganglionic connections of the nervous pathways to the eye concerned with the regulation of aqueous formation or in the control of its outflow may also be involved.

The effect of hypotensive anaesthesia with hexamethonium in arresting bleeding into the anterior chamber associated with hyphaema has been observed. ${ }^{1014}$ Trimetaphan (Arfonad) is a short-acting ganglion blocking agent administered by continuous intravenous infusion. No studies have been reported on the effects of trimetaphan-induced low-tension anaesthesia on the intraocular pressure. It was therefore decided to study these effects in 5 patients undergoing routine dacryocystorhinostomy. 
Fig. 1 Variation of intraocular pressure with systemic blood pressure.

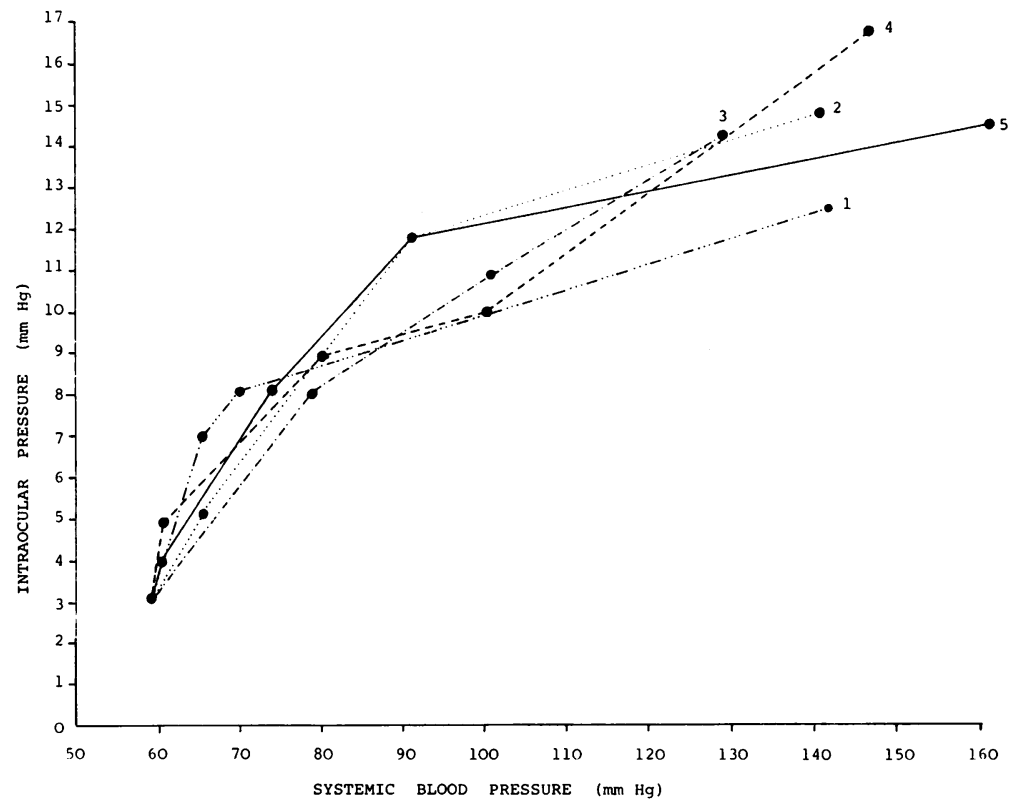

constant there was no significant change in the intraocular pressure. The maximal lowering of the intraocular pressure recorded in this group was a reduction of $3 \mathrm{mmHg}$ occurring soon after induction of general anaesthesia and was probably due to the induction procedure.

In all 5 patients undergoing dacryocystorhinostomy a lowering of the systolic blood pressure to $60 \mathrm{mmHg}$ produced a dramatic fall in the intraocular pressure to between 3-4 $\mathrm{mmHg}$ from the preoperative level of between 13-17 mmHg (Fig. 1). The intraocular pressure was observed to remain steady at this low level throughout the entire period during which the patient was under hypotensive anaesthesia. The maximal lowering of intraocular pressure was observed when the systolic blood pressure fell to $60 \mathrm{mmHg}$, and a rise of systolic blood pressure above $60 \mathrm{mmHg}$ was associated with a corresponding rise in the intraocular pressure (Table 1). At no stage was the systolic blood pressure allowed to fall below $60 \mathrm{mmHG}$.

\section{Discussion}

Anatomically the eye has 2 separate systems of blood vessels - the retinal and uveal. The uveal vessels are peculiar in that they possess no precapillary sphincter, which is responsible for opening and closing the capillaries, with the result that the flow of blood in the uveal vessels is steady and not alternating ${ }^{16}$ and there is a very high rate of blood flow through the uveal vessels.

In contrast to the kidney and brain, where owing to
In the 12 patients undergoing cataract surgery in whom the systemic blood pressure was maintained 
Table 1 Blood pressure and intraocular pressure recordings at 5-minute intervals in 5 patients undergoing hypotensive anaesthesia

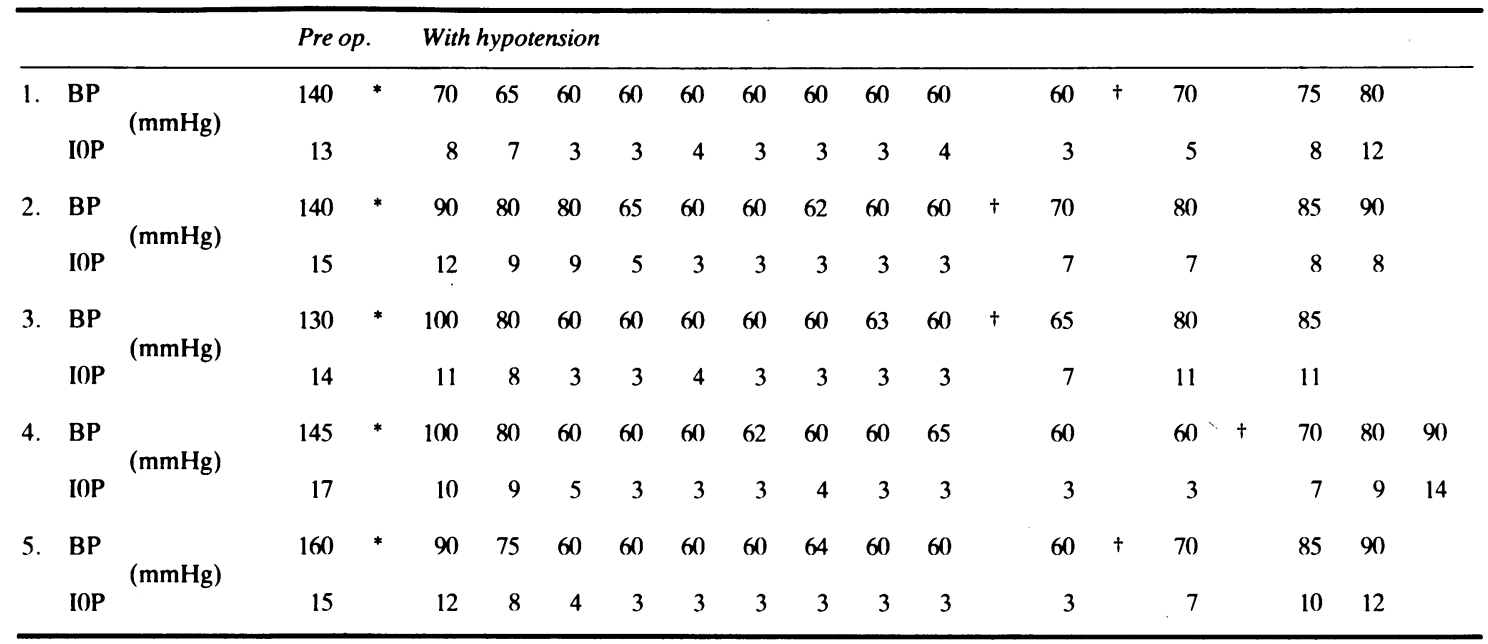

Points at which the intravenous trimetaphan drip was started* and stoppea ${ }^{*}$.

autoregulation a fall in perfusion pressure produces vasodilatation, thus maintaining a steady flow, there is no compensatory mechanism in the choroid, and the blood flow falls in proportion to the fall in perfusion pressure. ${ }^{17}$ Though there is no reflex which significantly stabilises the intraocular pressure when the arterial blood pressure drops, a reflex mechanism does exist to protect the eye against a marked rise in pressure with systemic hypertension. ${ }^{4}$

A transverse section of the choroid shows it to be made up almost entirely of a series of blood vessels, and because of this 'erectile' potential of its vascular channels the choroid undoubtedly plays a role in the regulation of intraocular pressure. As the volume of the vascular bed of the choroidal circulation is several times that of the retinal circulation, the former makes a greater contribution to the maintenance of intraocular volume and intraocular pressure. Since it is mainly the degree of filling of the choriocapillaris and other blood vessels of the choroid which determines the volume of blood in the interior of the eye and hence the intraocular pressure, a systemic hypotension which reduces the blood flow in the choroid produces a sudden fall in intraocular pressure. This was clearly demonstrated in the rabbit, where the effect of carotid clamping was an immediate fall in intraocular pressure in the ipsilateral eye and a dramatic reduction in the blood flow through the choroid. ${ }^{18}$ Stimulation of the peripheral end of the cut cervical sympathetic trunk caused a constriction of the uveal vessels, producing a reduced uveal blood flow and a marked fall in intraocular pressure. If the eyeball was enucleated or if the circulation of blood to the eye was interrupted, the intraocular pressure fell immediately. A rhythmic variation of the intraocular pressure occurring in phase with the cardiac cycle due to alterations in the volume of the vascular bed of the eye has also been demonstrated. ${ }^{19}$ It is thus apparent that any factor which changes the filling of the choroidal reservoir must affect the intraocular pressure immediately.

The two fluids in the eye-blood and aqueous humour-contribute to the volume of the intraocular contents, and variations in the amount of either on account of a systemic hypotension will alter the intraocular pressure considerably. Formation of aqueous is partly due to secretion (75\%) and partly due to ultrafiltration $(25 \%)$. Ultrafiltration is the result of the hydrostatic pressure within the capillaries of the ciliary processes and is dependent on the ciliary artery blood pressure. If the systemic blood pressure falls, ultrafiltration is reduced as the blood supply to the ciliary body is reduced,${ }^{20}$ but secretion is not affected until the blood pressure falls to very low levels. It has been shown that the formation of aqueous persists in monkeys even at very low arterial pressure. ${ }^{21}$ Hence. unless there is extreme systemic hypotension, formation of aqueous continues by the process of secretion.

It is known that the latent period associated with the rise in intraocular pressure which follows a rise in blood pressure is $0 \cdot 1 \mathrm{~s}$, and no mechanism other than the distension of the choriocapillaris could adapt so rapidly. It is unlikely that the rise in intraocular pressure is due to increased aqueous formation, in which 
case the latent period is bound to be longer. The rapid influx of blood into the choriocapillaris produced an immediated steep but transient elevation of intraocular pressure. ${ }^{22}$ Our results show that a similar process could account for the fall in intraocular pressure which follows systemic hypotension, because a fall in intraocular pressure was observed with each stage of lowering of systemic blood pressure, the maximum fall in intraocular pressure occurring when the systolic blood pressure was reduced to $60 \mathrm{mmHg}$. Changes in intraocular pressure were almost exactly parallel to those in brachial artery blood pressure.

Thus it is more likely that the immediate and marked fall in intraocular pressure associated with systemic hypotension is due to a reduction in the volume of the vascular bed, and the persistence of the low intraocular pressure is due to the decreased formation of aqueous consequent upon the reduced flow of blood through the ciliary processes.

\section{References}

1 Kais MA. Sears ML. Hormonal regulation of intraocular pressure. Surv Ophthalmol 1977; 2: 153-76.

2 Bill A. Intraocular pressure and blood flow through the uvea. Arch Opthalmol 1962; 67: 336-48.

3 Cohan BE, Cohan SB. Anterior ciliary venous blood flow and oxygen saturation at reduced arterial pressure. Am J Physiol 1963; 205: 67-70.

4 Adler FE. Physiology of the eve. St Louis: Mosby, 1959.

5 Joshi C. Bruce DL. Thiopental and succinyl choline action on intraocular pressure. Anesth Analg (Cleve) 1975: 54: 471-5.

6 Duncalf D. Foldes FF. Effect of anaesthetic drugs and muscle relaxants on intraocular pressure. Int Ophthalmol Clin 1973: 13: 21-33.

7 Marynen L. Libert T. Ocular tonometry in the child under general anaesthesia with IM ketamine. Acta Anaesthesiol Belg 1976; 27: 29-40.

8 Cook JH. The effect of suxamethonium on intraocular pressure. Anaesthesia 1981; 36: 359-65.

9 Rycroft BW. Romanes GJ. Preliminary report on the use of methonium compound and general anaesthesia in ophthalmic surgery. Br J Ophthalmol 1952; 36: 29-36.

10 Kenny S. Hyphema and raised intraocular pressure. Am J Ophthalmol 1959; 47: 697-700.

11 Barnett AJ. Ocular effects of methonium compounds. $\mathrm{Br} \mathrm{J}$ Ophthalmol 1952; 36: 593-602.

12 Niesel A. Quoted in Duke-Elder S. System of Ophthalmology. London: Kimpton, 1968: 4: 94.

13 Drucker AP. Sandove MS. Unna KR. Ocular manifestations of intravenous tetraethyl ammonium chloride in man. Am J Ophthalmol 1950; 33: 1564-7.

14 Moore JG. Youngman PME. Secondary traumatic hyphaema. Br J Ophthalmol 1968; 52: 172-3.

15 Perkins ES. Handheld applanation tonometer. Br J Ophthalmol 1965; 49: 191-6.

16 Friedman E. Oak SM. Choroidal microcirculation in vivo. Bibl Anat 1965; 7: 129-36.

17 Alm A. Bill A. The oxygen supply to the retina. Acta Physiol Scand 1972; 84: 306-24.

18 Broadfoot KD, Gloster J. Greaves DP. Photoelectric method of investigating the amount and oxygenation of blood in the fundus oculi. Br J Ophthalmol 1961; 45: 161-82.

19 Bettman JW. Fellows V. Factors influencing the blood volume of the choroid and retina. Am J Ophthalmol 1958; 46: 1-10.

20 Kornbleuth W. Nawratzki I. Gabbay A. The effect of extraocular muscle surgery on aqueous humour dynamics. Am J Ophthalmol 1959; 48: 321-6.

21 Bill A. The role of ciliary blood flow and ultrafiltration in aqueous humour formation. Exp Eye Res 1973; 16: 287-98.

22 Casey WJ. Aqueous humour dynamics. In: Duane TD, ed. Clinical ophthalmology. London: Harper and Row. 1975: 3: 3. 